\title{
Intrathoracic pressure oscillations during obstructive apneas disturb ventricular repolarisation
}

\author{
Dominik Linz $\cdot$ Klaus Wirth
}

Received: 23 July 2012/ Accepted: 26 August 2012/Published online: 5 September 2012

(C) Springer-Verlag 2012

Camen et al. (2012) demonstrated that simulated obstructive apnea and hypopnea in patients are associated with an increase in ventricular premature beats and prolongation of ventricular repolarisation, suggesting that negative intrathoracic pressure changes during obstructive apneas may contribute to increased cardiac dysrhythmias in obstructive sleep apnea (OSA). The authors speculate that increased sympathetic activation, which has previously been shown to be present in patients with OSA and during experimentally simulated obstructive apneas, may explain altered arrhythmogenic cardiac electrophysiology during obstructive apneas.

Previously, our group (Linz et al. 2011) showed in a pig model of OSA that forced inspiration against the obstructed upper airways results in substantial negative tracheal pressure (NTP) down to about -60 to $-80 \mathrm{cmH}_{2} \mathrm{O}$, representing a strong trigger for atrial fibrillation (AF) compared to hypoxia alone. Applied strong NTP causes a pronounced shortening of the atrial effective refractory period and increased susceptibility to AF. Interestingly, NTP-induced atrial effective refractory period shortening was modulated by atropine or atenolol. In addition, the modulation of autonomic nervous system by renal sympathetic denervation displayed pronounced antiarrhythmic effects in the pig model for OSA (Linz et al. 2012). These findings emphasize the importance of autonomic imbalance in OSA-associated

Communicated by Susan A. Ward.

D. Linz $(\bowtie)$

Cardiology, Uniklinikum des Saarlandes,

Kirrberger Str., 66424 Homburg/Saar, Germany

e-mail: dominik.linz@gmx.de

K. Wirth

Cardiovascular, Sanofi, Industriepark Hoechst,

Frankfurt, Germany
AF. Also, renal sympathetic denervation (RDN) has also been shown to reduce OSA-severity in hypertensive patients as well as blood pressure (Witkowski et al. 2011).

The first data supportive for potential antiarrhythmic effect of acute RDN in the ventricle have recently been published (Ukena et al. 2012). These authors reported reduced ventricular tachyarrhythmias in patients with electrical storm and congestive heart failure after renal sympathetic denervation. Whether modulation of the autonomic nervous system is effective in influencing ventricular arrhythmogenic changes in OSA is unknown, and deserves to be tested in experimental and clinical studies.

\section{References}

Camen G, Clarenbach CF, Stöwhas AC, Rossi VA, Sievi NA, Stradling JR, Kohler M (2012) The effects of simulated obstructive apnea and hypopnea on arrhythmic potential in healthy subjects. Eur J Appl Physiol. doi:10.1007/s00421-0122457-y

Linz D, Schotten U, Neuberger HR, Böhm M, Wirth K (2011) Negative tracheal pressure during obstructive respiratory events promotes atrial fibrillation by vagal activation. Heart Rhythm 8:1436-1443

Linz D, Mahfoud F, Schotten U, Ukena C, Neuberger HR, Wirth K, Böhm M (2012) Renal sympathetic denervation suppresses postapneic blood pressure rises and atrial fibrillation in a model for sleep apnea. Hypertension 60:172-178

Ukena C, Bauer A, Mahfoud F, Schreieck J, Neuberger HR, Eick C, Sobotka PA, Gawaz M, Böhm M (2012) Renal sympathetic denervation for treatment of electrical storm: first-in-man experience. Clin Res Cardiol 101:63-67

Witkowski A, Prejbisz A, Florczak E, Kądziela J, Śliwiński P, Bieleń P, Michałowska I, Kabat M, Warchoł E, Januszewicz M, Narkiewicz K, Somers VK, Sobotka PA, Januszewicz A (2011) Effects of renal sympathetic denervation on blood pressure, sleep apnea course, and glycemic control in patients with resistant hypertension and sleep apnea. Hypertension 58:559-565 